International Journal of Sports Medicine and Rehabilitation
(ISSN:2637-5044)

\title{
Progressive exercise therapy in muscle dystrophy: two case studies in adult patients with DM2 and LGMD2D
}

\author{
Nico Nitzsche ${ }^{1^{*}}$, Noah Augustin ${ }^{1}$, Michael Klotz $^{1}$, Henry Schulz ${ }^{1}$ \\ ${ }^{1}$ Professorship of Sports Medicine/ Sports Biology, TU Chemnitz, Thüringer Weg 11, 09126 Chem- \\ nitz, Germany.
}

\section{ABSTRACT}

These two case studies aimed to investigate the effect and acceptance of progressive strength training in patients with muscular dystrophy. Case 1 completed a progressive *Correspondence to Author: resistance exercise over 12 weeks. The results showed increases in leg extensor strength, hand strength and balance. Furthermore, the anaerobic test showed an increase in the maximum glycolysis rate. Creatine kinase levels were reduced while maintaining low muscle soreness. Case 2 conducted seven weeks of electronically assisted strength training and electromyostimulation. In the course of the training, an increase in the self-contribution of the performance in the execution of movement was observed in the assisted strength training. Furthermore, an increase in the intensity of external stimuli was observed. The creatine kinase showed a reduction with physiological behavior of muscle soreness. The results demonstrate the acceptance and feasibility of progressive exercise protocols used to increase performance in two cases of muscular dystrophy.

Dr. Dr. Nico Nitzsche

Professorship of Sports Medicine / Sports Biology, TU Chemnitz, Thüringer Weg 11, 09126 Chemnitz, Germany. Email: nico.nitzsche@ hsw.tu-chemnitz.de; Tel: +49 371 53137326

\section{How to cite this article:}

Nico Nitzsche, Noah Augustin, Michael Klotz, Henry Schulz. Progressive exercise therapy in muscle dystrophy: two case studies in adult patients with DM2 and LGMD2D. International Journal of Sports Medicine and Rehabilitation, 2021; $4: 17$.

Keywords: Muscle dystrophy; Resistance exercise; Exercise therapy; Muscle soreness; Creatine kinase

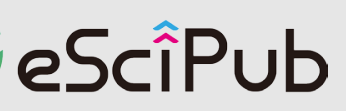

eSciPub LLC, Houston, TX USA. Website: https://escipub.com/ 


\section{Introduction}

Muscular dystrophy is a general term for diseases of the muscle fibers. This disease leads to a decrease in muscle mass and strength, especially in the pelvic and shoulder girdle muscles. There are more than 30 different forms of muscular dystrophies, which differ in the type of inheritance, the affected body region as well as in the age and development of the disease. The worldwide prevalence of muscular dystrophies is 16.14 [Cl: 11.21-23.23) per $100.000^{[24]}$.

The myotonic dystrophy (DM) is the most common muscle disease in adults and has a prevalence at 8.26 per 100.000 (Cl: 4.99-13.68) [24]. In Germany the incidence is about 1:15000 newborns and the prevalence at 1:37 000 [27]. Countries like Germany, Finland or Canada show a higher prevalence of DM2 compared to other European countries. Suominen et al. ${ }^{[37]}$ investigated the frequency of the disease in Finland and reported a prevalence of DM2 of 1:1830. The presence of muscular, extramuscular and cerebral symptoms is slightly different, but the frequency and severity of individual symptoms can vary significantly. A combination of progressive muscle weakness, myotonic symptoms, early lens opacity, cardiac arrhythmia and endocrine disorders is clinically indicative for both forms [25,32]. Myotonia is one of the most important muscular symptoms of DM1 and usually occurs in the distal muscle groups (e.g. forearm and lower leg muscles). Furthermore, muscle weakness with muscle atrophy occurs. Those affected can lose 30 to $55 \%$ of their maximum strength over a period of nine years. The pattern of progression is characterized by distal to proximal muscles [12]. DM2 is an adult disease and is generally milder and slower progression than DM1. Severe forms are possible in adulthood to mild forms in old age. The disease-related muscular weakness can lead to wheelchair use $(\sim 10 \%)$ and respiratory failure ${ }^{[42,43]}$. Muscular symptoms are among the most common complaints. According to Day et al. ${ }^{[8]}$, $82 \%$ suffer from muscle weakness, $75 \%$ from clinical myotonia and $56 \%$ from muscle pain (myalgia). The characteristic feature is proximal muscle weakness, which usually begins in the head and hip flexors, elbow extensors, hip extensors and finger flexors ${ }^{[8]}$.

Limb girdle muscular dystrophy (LGMD) is a disease of the muscle fibers, which is accompanied by paralysis and muscle fading. Six autosomal dominant (LGMD1A-F) and ten autosomal recessive (LGMD2A-J) forms are currently known. In LGMD2D, the SGCA gene, which is responsible for the formation of the protein alpha-sarcoglycan, is affected. LGMD is a rare hereditary disease in Germany and other parts of the world. The prevalence LGMD is estimated by 1.63 per 100.000 (Cl:0.94-2.81) [24]. In Europe, the prevalence of LGMD2D is estimated to be 3.9 per million [21]. In Germany, the incidence is estimated at 1:3080 000 $(\sim 0.325 \text { per million })^{[16]}$. Typical symptoms are paralysis and muscle atrophy. Especially the proximal, trunk muscles are affected. In the upper arms and thighs, the extensor muscles are affected more than the flexor muscles. In most cases, the thigh muscles are affected first, later the weakness also affects the shoulder muscles. Patients often suffer from low back pain, joint stiffness, joint contractures, and rapid fatigue ${ }^{[10]}$. Basically, muscular dystrophy shows not only a reduction in muscular performance but also a change in energy metabolism. Fontes-Oliveira, Steinz, Schneiderat, Mulder, and Durbeej [11] found a dysregulated expression of genes in energy production, with a reduction in PFK expression. The lactate concentration at rest and under/after exercise is comparable to that of healthy controls, but also significantly higher [34,41]. Furthermore, studies in patients and animal models show changes in glycolytic enzyme activity in patients with muscular dystrophy. Di Mauro, Angelini, and Catani [9] showed that the glycolytic enzymes PFK and LDH had only about $50 \%$ of the activity as in healthy subjects. It could also be shown that at the end of the exercise there were lower $\mathrm{pH}$ reductions and lower lactate concentrations compared to healthy controls [22]. This indicates 
a lower glycolytic activity in muscles of patients with muscular dystrophies.

\section{Exercise therapy}

Overall, endurance training, upper and lower extremity strength training, balance training, functional and neuromuscular electro stimulation and combined training studies are available for training in muscle dystrophy $[1,5,7,14,17,26,30,38,44]$. The efficacy of strength training has been demonstrated in patients with DM1 ${ }^{[19,20]}$. No significant effects on muscle strength, fatigue or functional performance have been found. Few studies show improvements in muscle endurance and an increase in quadriceps strength ${ }^{[19,20]}$. In a 12-week (3 times per week), progressive training program in 9 patients with DM1 ( $3 \times 10$ repetitions, $80 \%$ of the $1 \mathrm{RM})$, increases in knee extensor muscles were shown but without significant difference between the pre- and posttest in the isokinetic test ${ }^{[40]}$. A 6month strength training pro- gram in patients with LGMD at $60 \%$ of maximum strength leads to a significant increase in strength and endurance. HIT training can also achieve this effect, although it should be noted that some patients may drop out due to increases in CK. It can be stated that strength training can be safe and effective in LGMD but should always be carefully supervised [35].

The effects of training interventions were largely investigated using DM1 population. A review of 21 studies by Roussel, Morin, Gagnon, and Duchesne [31] summarized various effects of training, such as improved self-perception, increase in maximum strength, increase in aerobic capacity, improvement in respiratory function, stress-induced normalization of electromyographic patterns, slight increase in muscle volume, with increase of type 1 and type $2 \mathrm{a}$ fibers. The data show potentially significant effects of training in muscular dystrophy. However, due to the heterogeneity between the studies, it was not possible to identify training parameters for individual practical action. In order to show possible approaches to design a training therapy for muscle strengthening in muscular dystrophy, two case studies will be presented. The aim of the work was to show the effect of progressive muscle training based on two case studies with different clinical symptoms and severity.

Case 1 was a 45 year old male patient with DM2 $(71 \mathrm{~kg}, 174 \mathrm{~cm})$. The disease was clinically and molecularly confirmed in 2005 (Universitätsklinikum Magdeburg,Germany). At the time of diagnosis, the patient had been diagnosed with a highly elevated CK value. Through a muscle biopsy and molecular genetic tests, the diagnosis (PROMM) has been confirmed. The patient had been suffering from increasing muscle weakness for 2 years. In the family, DM2 was also confirmed in the mother and the grandmother suffered from cataracts. He reported back pain lumbar with partial radiation into the buttocks and dorsal side of the thighs. In addition, his hands tremble during exertion and he suffers from weakness in his legs when trying to stand up or when climbing stairs. At the time of diagnosis, the test person does not suffer from any muscle pain. However, the muscles of the legs cramp several times a day, especially at rest.

\section{Assessments}

Before (pretest), in the middle (6th week) and after the intervention (posttest), motor tests were carried out to determine physical performance. Isokinetic strength tests (motion velocity: $240^{\circ} \mathrm{s}$ 1, 10 reps, CON-TREX® MJ Fa. Physiomed, Schnaittach, Deutschland) were used to determine the performance (peak torque, PT) of the leg extensors and leg flexors as well as anaerobic performance based on the maximal lactate formation rate (vLamax). For the determination of vLamax, capillary blood samples were taken from the earlobe before, immediately after and up to the ninth minute after the test. The calculation of the vLa $a_{\max }$ was performed according to Mader [23]. The isometric hand strength was determined using a hand dynamometer. Furthermore, the maximum strength (1RM) was determined for all six training exercises. The $\mathrm{Y}$-balance test was performed to measure postural stability (composite reach score: CRS). At intervals of 
two weeks, venous blood samples were taken to determine the creatine kinase (CK) value. The training volume load was calculated according to Scott, Duthie, Thornton, \& Dascombe [33]. Muscle pain was recorded before and after each training session (Delayed onset muscle soreness: DOMS Scale 1-10).

\section{Exercise protocol}

The training intervention included a progressive resistance training over 12 weeks with 3 exercise sessions per week. At the beginning of each session, the patient warmed up for 5 minutes on a rowing ergometer. Before each exercise, two warming up sets were performed. The following exercises/devices were used: Leg press, chest press, lat pull, butterfly reverse, bicep curls and triceps press on the cable pull through. The pause time between the sets was $2 \mathrm{~min}$. During each unit a trainer supervised the correct execution of the exercises. The training protocol was progressively by increasing the load or the number of repetitions. Figure 1 shows the exercise volume (EV as weekly mean value of the total volume for all exercises) over time.

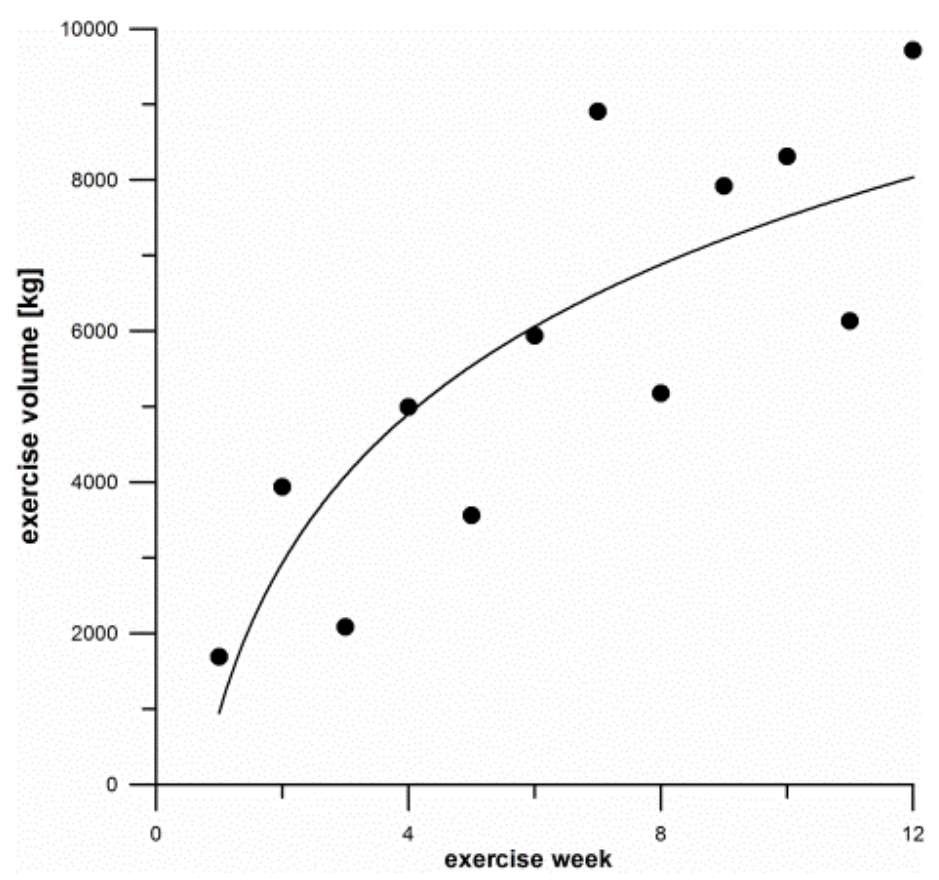

Figure 1: representation of the course of the exercise volume in case 1.

\section{Results}

The patient completed 33 of 36 training sessions (92\%). The EV was increased by manipulating load, number of repetitions and number of sets and tended to be flatter towards the end of the intervention. Performance in leg extensors and flexors showed an increase in PT in both legs from pretest to posttest (Figure 2). In the pretest, the CRS of the right leg was approximately $97 \%$ and of the left leg approximately $95 \%$. In the posttest, the right leg and the left leg reached to $107 \%$. The difference between the two legs and the posttest decreased. In the pretest the difference was about $2 \%$, in the intermediate test $3.9 \%$ and in the posttest only $0.6 \%$. In the pretest and interim test, the hand strength was 78 pounds. In the posttest, the increase was 87.5 pounds (compared to the pretest by 9.5 pounds, about $4.3 \mathrm{~kg}$ ). The vLamax increased from $0.04 \pm$ $0.02 \mathrm{mmol} \mathrm{l}^{-1} \mathrm{~s}^{-1}$ to $0.13 \pm 0.03 \mathrm{mmol} \mathrm{l}^{-1} \mathrm{~s}^{-1}$ in the posttest (3.5-fold increase). The CK decreased continuously from $15.29 \mu \mathrm{mol} \mathrm{I}^{-1} \mathrm{~s}^{-1}$ to $3.96 \mu \mathrm{mol}$ $\mathrm{I}^{-1} \mathrm{~s}^{-1}$, until the seventh week of training. From week eight on, the $\mathrm{CK}$ increased to $11.8 \mu \mathrm{mol} \mathrm{I}^{-}$ ${ }^{1} \mathrm{~s}^{-1}$ (cause given: fall down stairs). The DOMS showed an unchanged value at 1 .

Case 2 was a 25 years old male patient with LGMD2D (90 kg, $172 \mathrm{~cm})$. The disease was clinically confirmed in 1999 (Universitätsklinikum Leipzig, Germany). At the time of diagnosis, the patient had been diagnosed with a highly elevated CK value due to mononucleosis. 
Through a muscle biopsy and molecular genetic tests, the diagnosis of $\alpha$-Sarcoglycanopathy could be made (Muscle dystrophy also confirmed at grandmother, since she was 34 Years old). Since 2009 the patient is wheelchairbound and needs help with the transfer. Since
2013 he has been completely unable to walk and pain is felt in the lumbar, sciatic, ankle and shoulder-neck areas. A voluntary maximum contraction of the muscles is possible, not always visible, but mostly palpable.

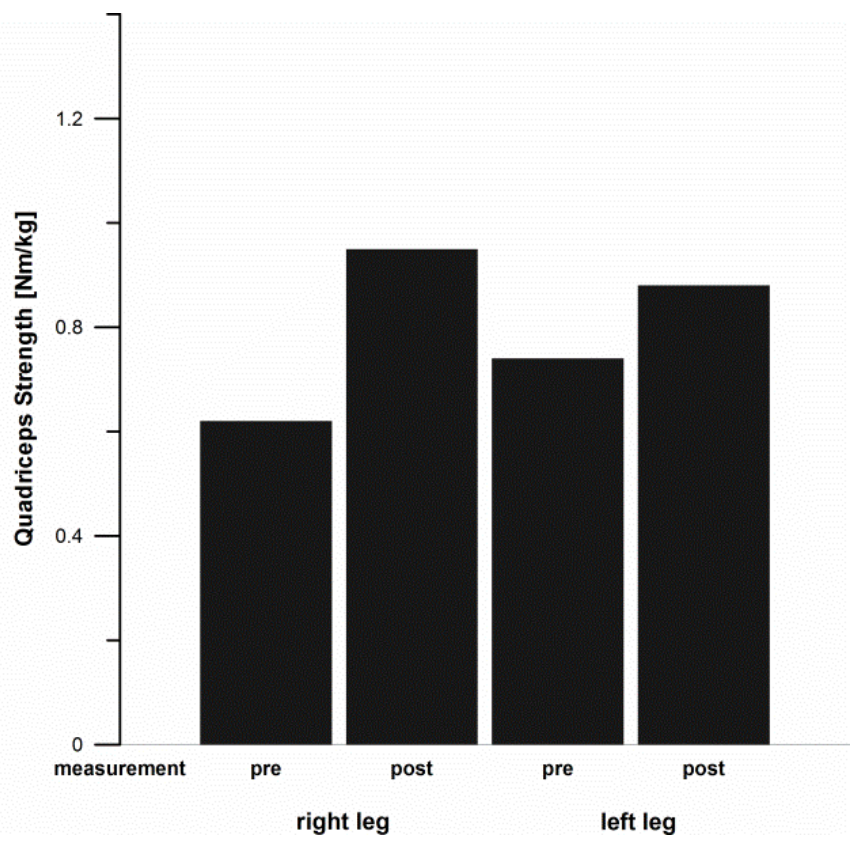

Figure 2: Strength of the knee extensors in the isokinetic test in case 1.

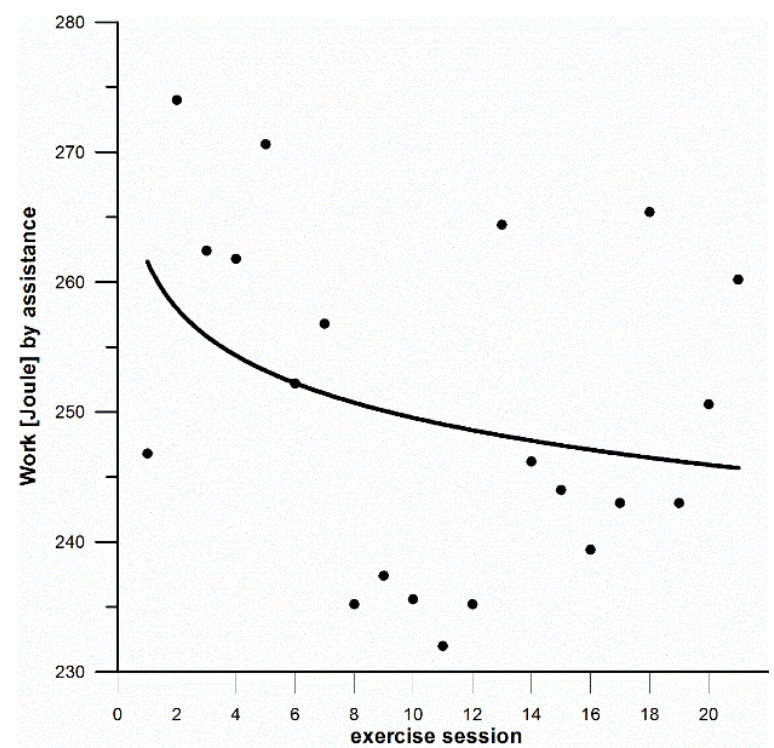

Figure 3: Work by assisted strength training dynamometer at every exercise session in case 2.

\section{Assessments}

Due to the limited mobility of the patient, no motor tests are performed. However, the performances recorded during the isokinetic training were used to assess the performance development. CK values were determined before the start of the training program, at weekly intervals and at the end of the intervention. Furthermore, a scale of muscle soreness (DOMS) before and several times after the training session (VAS 1-10) and the McGill Pain Questionnaire were used daily.

\section{Exercise protocol}

The patient performed three times per week an electronically supported training of the knee extensors (right leg) over seven weeks (CON- 
TREX® MJ Fa. Physiomed, Schnaittach, Germany). Due to the inability to extend the leg against gravity, five sets with thirty passiveassisted repetitions were performed. In this mode, the patient had the opportunity to contract during each movement cycle. The work (Joule) and torque $(\mathrm{Nm})$ performed by the patient was displayed as feedback. From the third week of training (six sessions were performed), additional EMS training $(50 \mathrm{~Hz}, 300 \mu \mathrm{s}, 10$ sets with 15 contractions per set, contraction time $2 \mathrm{~s}, 2 \mathrm{~s}$ rest) was performed on the right $M$. rectus femoris. The adjustment of the current intensity $(\mathrm{mA})$ was based on the subjective perception of the patient.

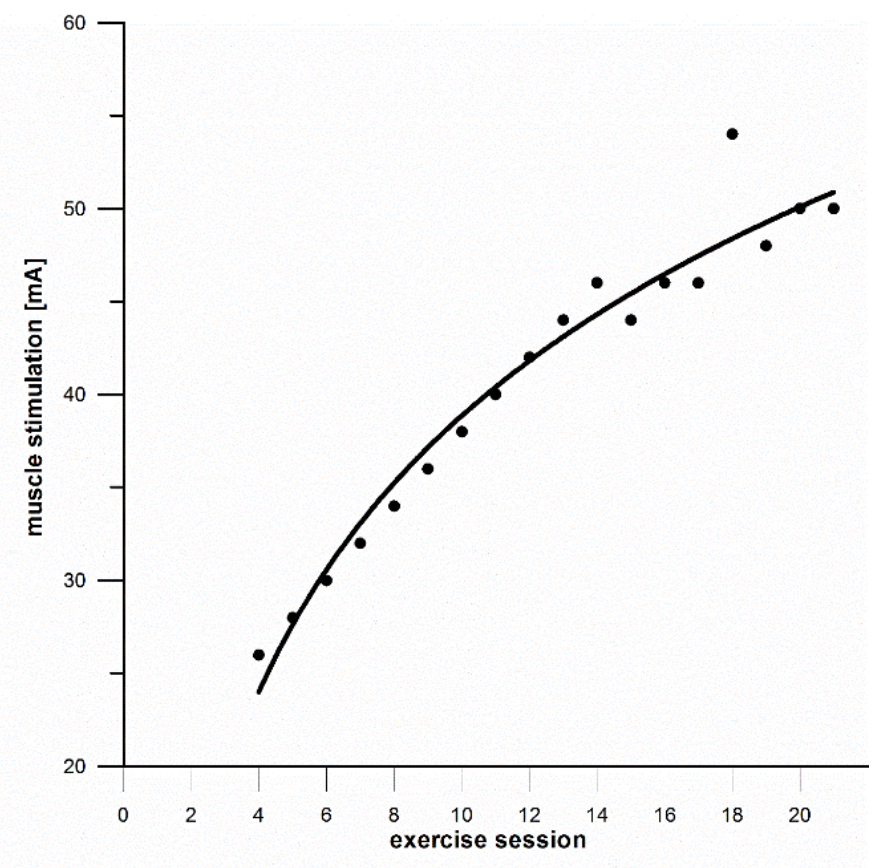

Figure 4: Progression of electrical muscle stimulation in case 2.

\section{Results}

The patient underwent 21 training sessions and showed a high level of motivation over the duration of the intervention and subjectively assessed general well-being as improved. The work performed by the training equipment during electronically supported training showed a decreasing tendency over the training units (Fig.3). This indicates that the patient was doing more work and was therefore more active in the movement cycle. In terms of EMS training, the applied voltage was increased from $26 \mathrm{~mA}$ to 46 $\mathrm{mA}$ until the seventh week of training (Fig.4). Prior to the intervention, the $\mathrm{CK}$ value was 13.33 $\mu \mathrm{mol} \mathrm{l}^{-1} \mathrm{~s}^{-1}$ and showed a continuous decrease to $7.64 \mu_{\mathrm{mol} \mathrm{I}}^{-1} \mathrm{~s}^{-1}$ until the seventh week of training. At week seven on, an increase to $10.66 \mu \mathrm{mol} \mathrm{I}^{-}$ ${ }^{1} \mathrm{~S}^{-1}$ was observed. The values of DOMS showed before training sessions $1.1 \pm 0.7$, immediately after training session $5.4 \pm 0.9,6.0 \pm 1.4$ hours after training a value of $5.4 \pm 1.1$ and after $20.5 \pm 1.2$ hours the DOMS was decreased at 3.1 1.1. The McGill Pain Questionnaire values showed $1.1 \pm 0.3$ in the overall pain assessment.

\section{Discussion}

The aim of these two case studies was to show the development of performance in progressive training design. Both patients showed a high level of compliance and acceptance throughout the intervention. Based on the different initial condition of both patients, active resistance training (case 1) and passive-assisted strengthening training (case 2) were used. The results of the isokinetic test (case 1) and the progress of work done in training (case 2) show improvements in performance, which were also subjectively perceived by the patients. The behavior of the exercise volume in case 1 and 
the applied intensity of electromyostimulation in case 2 show a possible approach to the training process. The load curves also show that further adjustments were to be expected beyond the intervention period, as no plateau had yet been reached. On the one hand, this is an indication of the patients' adaptability. On the other hand, it shows the feasibility and acceptance of a progressive training protocol. It is quite difficult to assess at what point in time changes in the load should be made. This would require studies that compare different training protocols on the basis of subjective and physiological parameters. Improvements in performance was also shown in other studies on DM1 patients, but the results were not statistically significant $[19,20,40]$. Effects of physical activity have been studied far less in DM2 patients. However, one case study also showed an improvement in the performance of the DM2-patient [36].

For LGMD the results are in line with Ansved [2] and Sveen et al. ${ }^{[39]}$. Currently, the course of the CK value was investigated in patients with muscular dystrophies who had constant or decreasing $\mathrm{CK}$ values during the intervention $[3,38,44]$. Since the daily variability of $\mathrm{CK}$ according to Gutenbrunner ${ }^{[13]}$ fluctuates around its mean value by $10-15 \%$ during everyday activities, the values measured in the course cannot be attributed exclusively to daily fluctuations. Furthermore, the continuous decrease in $\mathrm{CK}$ values over the intervention area indicates muscle adaptation, which indicates a decrease in tissue damage. Possibly this can be interpreted as an indicator for the preservation of the musculature.

Due to the reduction of enzymes of the energy metabolism in muscle dystrophy, the activity of glycolysis is slowed down [22]. The anaerobic isokinetic strength test in case 1 showed a 6 -fold reduced maximum glycolysis rate at the pretest when compared to healthy subjects [28]. The posttest showed a significant increase in the glycolysis rate. Studies in which multi-week resistance training was performed showed an increase in glycolytic enzymes and the maximum glycolysis rate ${ }^{[15,28]}$.
Muscle pain in muscular dystrophy patients was often not recorded since many subjects had early courses of the disease in which an exact pain evaluation was not focused. The low pain perception in the two cases during the sessions is positive for the acceptance of this training load. Dynamic resistance training is a combination of eccentric and concentric muscle work. Compared to concentric training, eccentric training causes greater muscle damage and thus more severe muscle pain ${ }^{[4]}$. In case 2 due to the combined form of loading, the perception of pain can be the result of both forms of tension. Training by electrical muscle stimulation in muscular dystrophy (type FSHD; 5x/week for 5 months) led to a reduction of subjectively perceived muscle pain ${ }^{[6]}$. Intensive resistance Training (e.g. calf lifting until full fatigue), which is associated with significant muscle damage, shows a pain maximum (DOMS) approx. 72 hours after training [29]. In case 2, the pain maximum was observed within approximately 6 hours after training and then decreased. It is assumed that an early onset of the pain maximum after training indicates a low level of muscle damage. In this case, this would indicate an acceptable training load. Particularly, patients with limb girdle dystrophy, who suffered from increasing muscle pain and elevated CK values, were sometimes forced to stop strength training studies [39]. Variations in the distribution of receptor types as well as different pain modulation contribute to increased variability of muscle pain perception between subjects [18].

According to studies, this advanced strength training protocol has positive effects in slowly progressive courses. Further studies, especially on long-term effects, are necessary to establish the treatment method. Currently, most forms of muscular dystrophy are symptomatically treated with physiotherapy [2]. Currently, physiotherapy and speech therapy are mainly used, little weight training and far too few therapy units (usually 2 per week). The results show that improvements in muscle function are possible even with longterm disease. These applied training weeks are only a small sample of the potential 
development. Despite the illness, the muscles are resilient and can adapt and promote the patients' independence. Such training can be better controlled by regular CK monitoring and can allow for stress control in individual cases.

\section{Conclusion}

The results demonstrate the acceptance and feasibility of the training protocols used to increase performance in two cases of muscular dystrophy. This allows an insight into the possible design of a training therapy with such patients. It is desirable that future training studies with several patients under progressive load show the development of performance.

\section{References}

[1] Aldehag, A. S., Jonsson, H., \& Ansved, T. [Tor] (2005). Effects of a hand training programme in five patients with myotonic dystrophy type 1 . Occupational Thera-py International, 12(1), 1427. https://doi.org/10.1002/oti.12

[2] Ansved, T. [T.] (2001). Muscle training in muscular dystrophies. Acta Physiologica Scandinavica, 171(3), 359-366.

https://doi.org/10.1046/j.1365-

201x.2001.00839.x

[3] Berthelsen, M. P., Husu, E. [E.], Christensen, S. B., Prahm, K. P. [K. P.], Vissing, J. [J.], \& Jensen, B. R. (2014). Anti-gravity training improves walking capacity and postural balance in patients with muscular dystrophy. Neuromuscular Disorders: NMD, 24(6), 492498.

https://doi.org/10.1016/j.nmd.2014.03.001

[4] Böning, D. (2002). Muskelkater. Retrieved from https://www.aerzteblatt.de/pdf.asp?id=30395

[5] Chisari, C., Bertolucci, F., Dalise, S., \& Rossi, B. (2013). Chronic muscle stimula-tion improves muscle function and reverts the abnormal surface EMG pattern in myotonic dystrophy: A pilot study. Journal of NeuroEngineering and Rehabilita-tion, 10(1), 94.

https://doi.org/10.1186/1743-0003-10-94

[6] Colson, S. S., Benchortane, M., Tanant, V., Faghan, J.-P., Fournier-Mehouas, M., Benaïm, C., . . Sacconi, S. (2010). Neuromuscular electrical stimulation training: $A$ safe and effective treatment for facioscapulohumeral muscular dystrophy pa-tients. Archives of Physical Medicine and Rehabilitation, 91(5), 697-702.

https://doi.org/10.1016/j.apmr.2010.01.019

[7] Cudia, P., Weis, L., Baba, A., Kiper, P., Marcante, A., Rossi, S., . . Piccione, F. (2016).
Effects of Functional Electrical Stimulation Lower Extremity Training in Myotonic Dystrophy Type I: A Pilot Controlled Study. American Journal of Phys-ical Medicine \& Rehabilitation, 95(11), 809-817. https://doi.org/10.1097/PHM.000000000000049 7

[8] Day, J. W., Ricker, K., Jacobsen, J. F., Rasmussen, L. J., Dick, K. A., Kress, W., . . . Ranum, L. P. W. (2003). Myotonic dystrophy type 2: Molecular, diagnostic and clinical spectrum. Neurology, 60(4), 657-664.

https://doi.org/10.1212/01.wnl.0000054481.849 78.f9

[9] Di Mauro, S., Angelini, C. [C.], \& Catani, C. (1967). Enzymes of the glycogen cycle and glycolysis in various human neuromuscular disorders. Journal of Neurology, Neurosurgery, and Psychiatry, 30(5), 411-415.

https://doi.org/10.1136/jnnp.30.5.411

[10] Finsterer, J. (2004). Klinik und Genetik der Gliedergürteldystrophien [Limb girdle muscular dystrophies]. Der Nervenarzt, 75(12), 11531166. https://doi.org/10.1007/s00115-004-17695

[11] Fontes-Oliveira, C. C., Steinz, M., Schneiderat, P., Mulder, H., \& Durbeej, M. (2017). Bioenergetic Impairment in Congenital Muscular Dystrophy Type $1 \mathrm{~A}$ and Leigh Syndrome Muscle Cells. Scientific Reports, 7(1), 45272. https://doi.org/10.1038/srep45272

[12] Gagnon, C. [Cynthia], Petitclerc, É., Kierkegaard, M. [Marie], Mathieu, J., Duchesne, É., \& Hébert, L. J. (2018). A 9-year followup study of quantitative muscle strength changes in myotonic dystrophy type 1 . Journal of Neurology, 265(7), 1698-1705. https://doi.org/10.1007/s00415-018-8898-4

[13] Gutenbrunner, C. (2000). Circadian variations of the serum creatine kinase level--a masking effect? Chronobiology International, 17(4), 583590. https://doi.org/10.1081/CBI-100101065

[14] Hammarén, E., Lindberg, C., \& Kjellby-Wendt, G. (2015). Effects of a balance exer-cise programme in myotonic dystrophy type 1: A pilot study. European Journal of Physiotherapy, 17(3), 123-131. https://doi.org/10.3109/21679169.2015.104920 4

[15] Haun, C. T., Vann, C. G., Osburn, S. C., Mumford, P. W., Roberson, P. A., Romero, M. A., . . Roberts, M. D. (2019). Muscle fiber hypertrophy in response to 6 weeks of highvolume resistance training in trained young men is largely at-tributed to sarcoplasmic hypertrophy. PloS One, 14(6), e0215267. 
https://doi.org/10.1371/journal.pone.0215267

[16] Kenner, J. E. (2011). Inzidenzschätzung der Gliedergürtelmuskeldystrophien für Deutschland. Universität Würzburg. Retrieved from https://opus.bibliothek.uniwuerzburg.de/frontdoor/index/index/docld/6390

[17] Kierkegaard, M. [M.], Harms-Ringdahl, K., Edström, L., Widén Holmqvist, L., \& Tollbäck, A. (2011). Feasibility and effects of a physical exercise programme in adults with myotonic dystrophy type 1: A randomized controlled pilot study. Journal of Rehabilitation Medicine, 43(8), 695-702. https://doi.org/10.2340/165019770833

[18] Komi, P. V. (2003). Strength and Power in Sport. Oxford, UK: Blackwell Science Ltd. https://doi.org/10.1002/9780470757215

[19] Lindeman, E., Leffers, P., Spaans, F., Drukker, J., Reulen, J., Kerckhoffs, M., \& Koke, A. (1995). Strength training in patients with myotonic dystrophy and he-reditary motor and sensory neuropathy: A randomized clinical trial. Archives of Physical Medicine and Rehabilitation, 76(7), 612-620. https://doi.org/10.1016/s0003-9993(95)80629-6

[20] Lindeman, E., Spaans, F., Reulen, J., Leffers, P., \& Drukker, J. (1999). Progressive resistance training in neuromuscular patients. Effects on force and surface EMG. Journal of Electromyography and Kinesiology, 9(6), 379384. https://doi.org/10.1016/S1050-6411(99)00003-6

[21] Liu, W., Pajusalu, S., Lake, N. J., Zhou, G., loannidis, N., Mittal, P., . . . Lek, M. (2019). Estimating prevalence for limb-girdle muscular dystrophy based on public sequencing databases. (1-9): Genetics in Medicine. https://doi.org/10.1101/502708

[22] Lodi, R., Kemp, G. J., Muntoni, F., Thompson, C. H., Rae, C., Taylor, J., . . . Tay-lor, D. J. (1999). Reduced cytosolic acidification during exercise suggests defec-tive glycolytic activity in skeletal muscle of patients with Becker muscular dys-trophy. An in vivo 31P magnetic resonance spectroscopy study. Brain, 122 (Pt 1)(1), 121130. https://doi.org/10.1093/brain/122.1.121

[23] Mader, A. (1994). Die Komponenten der Stoffwechselleistung in den leichtathletischen Ausdauerdisziplinen-Bedeutung für die Wettkampfleistung und Möglichkeiten zu ihrer Bestimmung.: Neue Tendenzen im Ausdauertraining, 12

[24] Mah, J. K., Korngut, L., Fiest, K. M., Dykeman, J., Day, L. J., Pringsheim, T., \& Jette, N. (2016). A Systematic Review and Meta-analysis on the Epidemiology of the Muscular Dystrophies. The
Canadian Journal of Neurological Sciences. Le Journal Canadien Des Sciences Neurologiques, 43(1), 163-177. https://doi.org/10.1017/cjn.2015.311

[25] Meola, G. [Giovanni] (2013). Clinical aspects, molecular pathomechanisms and management of myotonic dystrophies. Acta Myologica: Myopathies and Cardi-omyopathies: Official Journal of the Mediterranean Society of Myology, 32(3), 154-165. Retrieved from https://pubmed.ncbi.nlm.nih.gov/24803843/

[26] Missaoui, B., Rakotovao, E., Bendaya, S., Mane, M., Pichon, B., Faucher, M., \& Thoumie, P. (2010). Posture and gait abilities in patients with myotonic dystro-phy (Steinert disease). Evaluation on the short-term of a rehabilitation program. Annals of Physical and Rehabilitation Medicine, 53(6-7), 387-398. https://doi.org/10.1016/j.rehab.2010.06.004

[27] Neumayr, A. (2008). Häufigkeit der proximalen myotonen Myopathie (PROMM/DM2) im Vergleich zur Myotonen Dystrophie (DM1) in der deutschen Bevölkerung. Re-trieved from https://www.researchgate.net/publication/27486 552 Haufigkeit der proximalen myotonen My opathie_PROMMDM2 im_Vergleich_zur_Myot onen Dystrophie DM1 in der deutschen Bev olkerung

[28] Nitzsche, N., Lenz, J. C., Voronoi, P., \& Schulz, H. (2020). Adaption of Maximal Glycolysis Rate after Resistance Exercise with Different Volume Load. Sports Medicine International Open, 4(2), E39-E44. https://doi.org/10.1055/a-1146-4236

[29] Northoff, H. (2013). Exercise Immunolgy Review: An official Publication of ISEI and DGSP. (19).

[30] Orngreen, M. C., Olsen, D. B., \& Vissing, J. [John] (2005). Aerobic training in pa-tients with myotonic dystrophy type 1 . Annals of Neurology, 57(5), 754-757. https://doi.org/10.1002/ana.20460

[31] Roussel, M.-P., Morin, M., Gagnon, C. [C.], \& Duchesne, E. (2019). What is known about the effects of exercise or training to reduce skeletal muscle impairments of patients with myotonic dystrophy type 1? A scoping review. BMC Musculoskele-tal Disorders, 20(1), 101. https://doi.org/10.1186/s12891-019-2458-7

[32] Schoser, B. [Benedikt], \& Timchenko, L. (2010). Myotonic dystrophies 1 and 2: Complex diseases with complex mechanisms. Current Genomics, 11(2), 77-90. https://doi.org/10.2174/138920210790886844

[33] Scott, B. R., Duthie, G. M., Thornton, H. R., \& Dascombe, B. J. (2016). Training Monitoring for 
Resistance Exercise: Theory and Applications. Sports Medicine, 46(5), 687-698.

https://doi.org/10.1007/s40279-015-0454-0

[34] Siciliano, G., Mancuso, M., Tedeschi, D., Manca, M., Renna, M., Lombardi, V., . . Murri, L. (2001). Coenzyme Q10, exercise lactate and CTG trinucleotide expan-sion in myotonic dystrophy. Brain Research Bulletin, 56(3-4), 405-410.

https://doi.org/10.1016/S0361-9230(01)00653-0

[35] Siciliano, G., Simoncini, C., Giannotti, S., Zampa, V., Angelini, C. [C.], \& Ricci, G. (2015). Muscle exercise in limb girdle muscular dystrophies: Pitfall and ad-vantages. Acta Myologica, 34(1), 3-8.

[36] Smith, K., \& Pucillo, E. (2018). The High-Level Mobility Assessment Tool (HiMAT) in Myotonic Dystrophy Type 2: A Case Report. SOAR@USA Physical Therapy Collection. Retrieved from https://soar.usa.edu/pt/24

[37] Suominen, T., Bachinski, L. L., Auvinen, S., Hackman, P., Baggerly, K. A., Ange-lini, C. [Corrado], . . . Udd, B. [Bjarne] (2011). Population frequency of myotonic dystrophy: Higher than expected frequency of myotonic dystrophy type 2 (DM2) mutation in Finland. European Journal of Human Genetics: EJHG. (7), 776-782. https://doi.org/10.1038/ejhg.2011.23

[38] Sveen, M. L., Jeppesen, T. D., Hauerslev, S., Køber, L., Krag, T. O. [T. O.], \& Vissing J. (2008). Endurance training improves fitness and strength in patients with Becker muscular dystrophy. Brain: A Journal of Neurology, 131(Pt 11), 2824-2831. https://doi.org/10.1093/brain/awn189
[39] Sveen, M.-L., Andersen, S. P., Ingelsrud, L. H., Blichter, S., Olsen, N. E., Jønck, S., . . Vissing, J. [John] (2013). Resistance training in patients with limb-girdle and becker muscular dystrophies. Muscle \& Nerve, 47(2), 163-169. https://doi.org/10.1002/mus.23491

[40] Tollbäck, A., Eriksson, S., Wredenberg, A., Jenner, G., Vargas, R., Borg, K., \& Ansved, T. [T.] (1999). Effects of high resistance training in patients with myo-tonic dystrophy. Scandinavian Journal of Rehabilitation Medicine, 31(1), 9-16.

[41] Tramonti, C., Dalise, S., Bertolucci, F., Rossi, B., \& Chisari, C. (2014). Abnormal Lactate Levels Affect Motor Performance in Myotonic Dystrophy Type 1. Euro-pean Journal of Translational Myology, 24(4), 4726. https://doi.org/10.4081/ejtm.2014.4726

[42] Udd, B. [B.], Meola, G. [G.], Krahe, R. [R.], Wansink, D. G., Bassez, G., Kress, W., ... . Moxley, R. (2011). Myotonic dystrophy type 2 (DM2) and related disorders report of the 180th ENMC workshop including guidelines on diagnostics and man-agement 3-5 December 2010, Naarden, The Netherlands. Neuromuscular Dis-orders, 21(6), 443-450. https://doi.org/10.1016/j.nmd.2011.03.013

[43] Udd, B. [Bjarne], \& Krahe, R. [Ralf] (2012). The myotonic dystrophies: Molecular, clinical, and therapeutic challenges. The Lancet Neurology, 11(10), 891-905. https://doi.org/10.1016/S1474-4422(12)70204-1

[44] Vissing, C. R., Preisler, N., Husu, E. [Edith], Prahm, K. P. [Kira P.], \& Vissing, J. [John] (2014). Aerobic training in patients with anoctamin 5 myopathy and hy-perckemia. Muscle \& Nerve, 50(1), 119-123. https://doi.org/10.1002/mus.24112

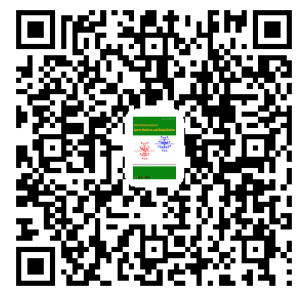

